\title{
THE DIFFERENCES BETWEEN TOED-IN CAMERA CONFIGURATIONS AND PARALLEL CAMERA CONFIGURATIONS IN SHOOTING STEREOSCOPIC IMAGES
}

\author{
H. Yamanoue \\ NHK Science and Technical Research Laboratories (Japan) \\ yamanoue.h-hk@nhk.or.jp
}

\begin{abstract}
A fundamental element of stereoscopic image production is to geometrically analyze the conversion from real space to stereoscopic images by binocular parallax under various shooting and viewing conditions. This paper reports on this analysis, particularly on the setting of the optical axes of 3D cameras, which has received little attention in the past. The parallel camera configuration maintains linearity during the conversion from real space to stereoscopic images. But the toed-in camera configuration often can not maintain linearity during the conversion from real space to stereoscopic images.
\end{abstract}

\section{INTRODUCTION}

Research into stereoscopic television is increasing in order to indicate one of the possibilities for new broadcasting services. The so-called stereoscopic image system, which creates stereoscopic effects by allocating a pair of images with binocular parallax between the human right and left eyes, provides a strong sensation of reality and powerful images much greater than ordinary 2D television. Owing to its relatively simple design, the system is increasingly used in both business and industrial applications such as for leisure activities and medical treatment. As broadcast programs are viewed by the general public over an extended period of time, it is important that 3D images look natural. We have therefore been researching appropriate shooting and viewing conditions.

Determining appropriate shooting and viewing conditions is equivalent to determining the method of converting from real space to stereoscopic images, which is one of the most fundamental tasks in constructing the stereoscopic image system. Great effort has been made on analyzing this conversion using binocular parallax as a parameter [1]-[4]. In particular, an orthostereoscopic condition under which the shooting space as a whole can be theoretically projected onto stereoscopic images has been examined [5][6]. Under the condition, the optical axes of the right and left lenses are kept apart and parallel to each other by the distance of right-left irises while an object is being shot. In conventional 3D television program production, on the other hand, these optical axes are made to cross at some point during the shooting because stereoscopic effects can be produced more easily in this way. These two different approaches, parallel and crossing optical axes, create significant differences not only in how stereoscopic effects are produced for programs, but also in the size and weight of
3D cameras (see Fig. 1)[7]. As the demand for efficient program production increases, it is very important to precisely understand the characteristics of these two ways of placing optical axes and to use them flexibly depending on the situation.

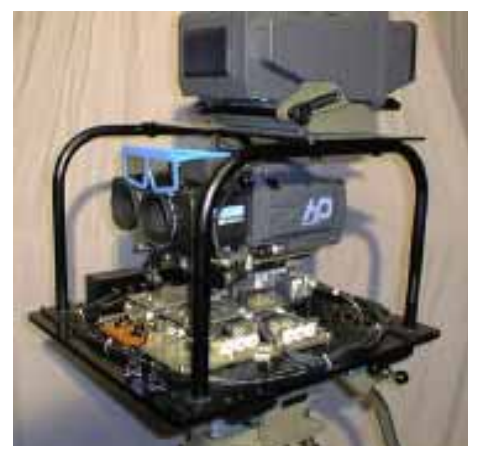

(1) Weight $25 \mathrm{Kg}$, no Zoom lens

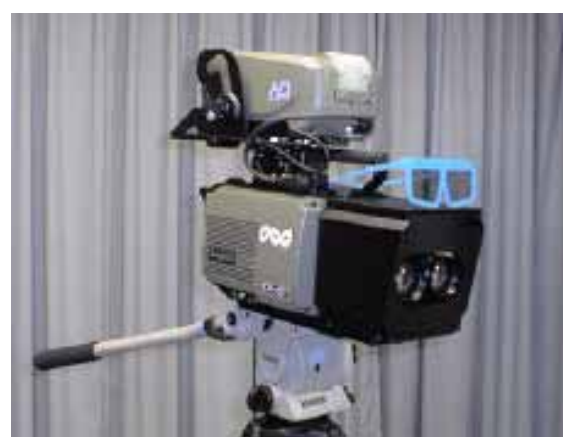

(2) Weight $8 \mathrm{Kg}$, with Zoom lens

Fig. 1 Crossing optical axes 3D HDTV camera (1) and Parallel optical axes 3D HDTV camera (2)

In this study, we attempted to geometrically analyze the conversion from real space to stereoscopic images by focusing on how optical axes are set, parallel or crossing (toed-in), a subject which has received little attention.

\section{CONDITIONS OF SETTING OPTICAL AXES IN STEREOSCOPIC SHOOTING}

\subsection{Shooting with parallel optical axes (parallel camera configuration)}

In this shooting method which keeps the optical axes parallel to each other, the concept is to create a horizontal linear shift between the right and left images during image acquisition or viewing so as to show the object, 
which is at an infinite point, at a point over an infinite distance. If as shown in Fig. 2 the distance between the two cameras (dc) and the horizontal shift between the right and left images $(\mathrm{Hc})$ are the same as the distance between the observer's right-left irises (de) and if the angles of view of the lenses and that of the display screen ( $\theta$ ) are the same, these satisfy distortion-free conditions under which the shooting space can be wholly reflected in stereoscopic images. These conditions set standards for conversion from real space to stereoscopic image space. It is not easy, however, to satisfy these conditions all the time in broadcasting where shooting and viewing conditions often vary. A more practical approach is required to deal with situations where these conditions are not met.

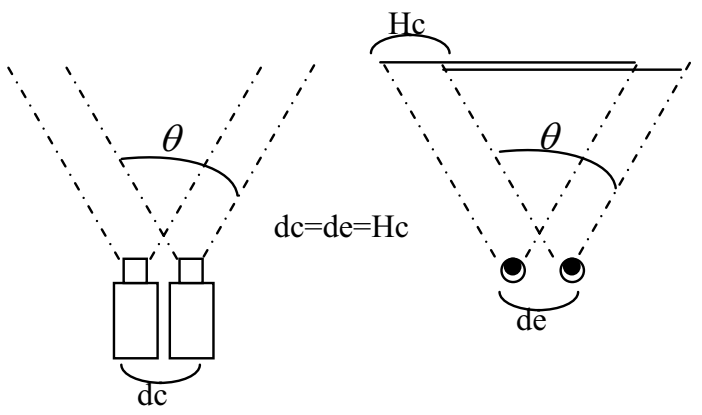

Fig. 2 An example of parallel camera configuration

\subsection{Shooting with crossed optical axes (toed-in camera configuration)}

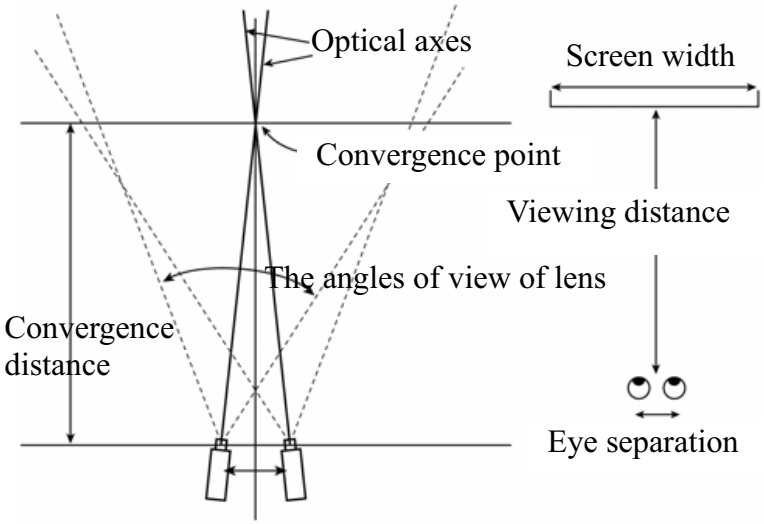

Fig. 3 An example of toed-in camera configuration

As shown in Fig. 3, this shooting method with crossed optical axes (hereafter referred to as the "toed-in camera configuration) has an object, which is at the point where the optical axes converge, reproduced on the screen as a stereoscopic image. The degree of stereoscopic effects, influenced by the camera separation, varies around this point where the optical axes converge. This means that it is possible to move where the image forms, toward or away from the viewer, by moving this convergence point back and forth. At the same time, the camera separation can be changed to adjust the amount of stereoscopic effect, the sensation of watching the image coming at you or moving away from you. Because these stereoscopic effects can be easily manipulated, this toed-in camera configuration is frequently used in television program production. However, visual distortions such as the puppet-theater effect and cardboard effect often accompany 3D pictures.

\section{CONVERSION FROM SHOOTING SPACE TO STEREOSCOPIC SPACE}

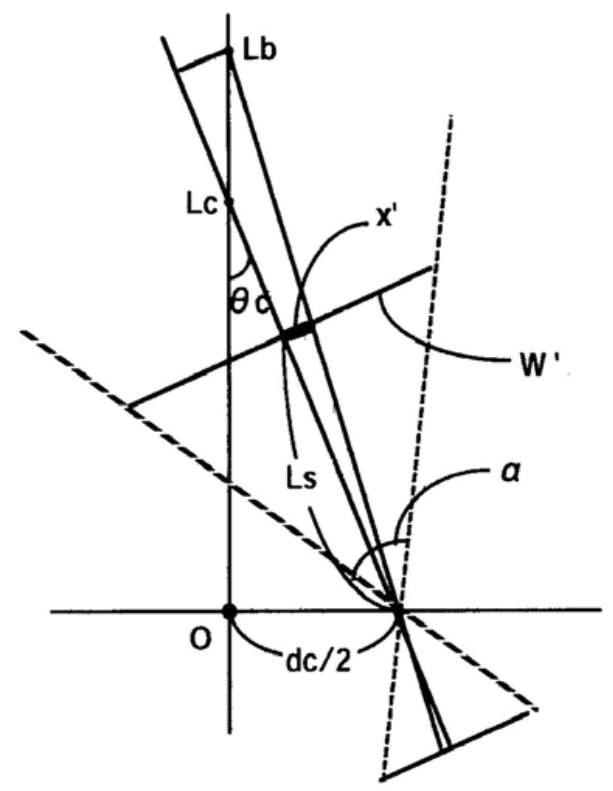

Fig. 4 A model of shooting system

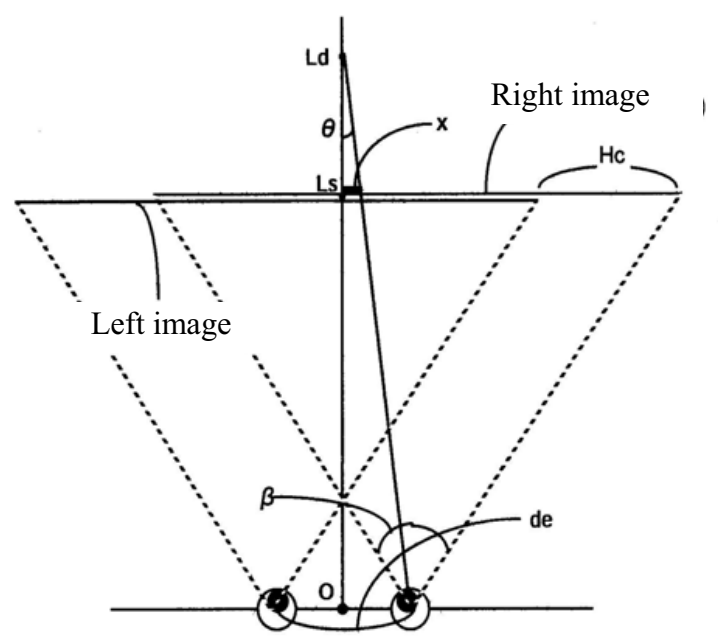

Fig. 5 A model of display system

Fig. 4 and 5 show models of the shooting and display systems. For simplicity, we use the center of an image free of keystone distortion. Parameters are shown in Table 1. 
Table 1 Parameters in shooting and display models

\begin{tabular}{|c|c|}
\hline $\mathrm{dc}$ & Camera separation \\
\hline de & Eye separation \\
\hline $\mathrm{Lb}$ & Shooting distance \\
\hline $\mathrm{Lc}$ & Convergence distance \\
\hline Ls & Viewing distance \\
\hline $\mathrm{Ld}$ & Position of a stereoscopic object \\
\hline$\alpha$ & Angles of view of lens \\
\hline$\beta$ & Viewing angle \\
\hline$\theta \mathrm{c}$ & Camera convergence angle \\
\hline$\theta$ & Convergence angle of eye \\
\hline $\mathrm{Hc}$ & $\begin{array}{l}\text { A horizontal gap between } \mathrm{L} \text { and } \mathrm{R} \\
\text { images }\end{array}$ \\
\hline W & The width of screen \\
\hline $\mathrm{W}^{\prime}$ & $\begin{array}{l}\text { The width of virtual screen at a viewing } \\
\text { distance in the shooting model }\end{array}$ \\
\hline $\mathrm{x}^{\prime}$ & $\begin{array}{l}\text { The distance from the center of the } \\
\text { virtual screen at a viewing distance in } \\
\text { the shooting model (see Fig. } 4 \text { ) }\end{array}$ \\
\hline
\end{tabular}

The following equation can be established from Fig. 4:

$\frac{\left(L_{b}-L_{c}\right) \sin \theta_{c}}{x^{\prime}}=\frac{\left(L_{b}-L_{c}\right) \cos \theta_{c}+\sqrt{\left(\frac{d_{c}}{2}\right)^{2}+L_{c}^{2}}}{L_{s}}$

In case of ordinary $3 \mathrm{D}$ program production, $\mathrm{dc}$ is several centimeters, and Lc ranges from several meters to several dozen meters. Assuming that $\theta_{c}$ is sufficiently small and that

$\sin \theta_{c} \cong \frac{d_{c}}{2 L_{c}}, \cos \theta_{c} \cong 1, \sqrt{\left(\frac{d_{c}}{2}\right)^{2}+L_{c}^{2}} \cong L_{c}$

we obtain:

$x^{\prime}=\frac{\left(L_{b}-L_{c}\right) \cdot d_{c} \cdot L_{s}}{2 L_{b} \cdot L_{c}}$

From Fig. 4 and Fig. 5, we obtain:

$x=\frac{W}{W^{\prime}} x^{\prime}+\frac{H_{c}}{2}$

With the angle of the eyes' convergence being $2 \theta$ when seeing a stereoscopic image, we derive:

$\tan \theta=\frac{d_{e}}{2 L_{d}}=\frac{1}{L_{s}} \cdot\left(\frac{d_{e}}{2}-x\right)$

where, we define camera separation ratio as $\frac{d_{c}}{d_{e}}=a_{1}$

and the magnification of an image on the retina as

$$
\frac{W}{W^{\prime}}=\frac{\tan \frac{\beta}{2}}{\tan \frac{\alpha}{2}}=a_{2}
$$

By substituting (2), (3), (5), and (6) into (4), we now have the final location, , where the stereoscopic image is formed:

$$
L_{d}=\frac{1}{\frac{1}{L_{s}}-\frac{a_{1} \cdot a_{2}}{L_{c}}+\frac{a_{1} \cdot a_{2}}{L_{b}}-\frac{H_{c}}{L_{s} \cdot d_{e}}}
$$

\subsection{Parallel camera configuration}

Here, we assume in equation (7) that the distance to the convergence point is infinite. As for $\mathrm{Hc}$, the horizontal shift of right-left images, we also assume that $\mathrm{Hc}=\mathrm{de}$ as the infinite point during the shooting will also be located at an infinite point during the viewing. With these assumptions, equation (7) can be simplified to:

$$
L_{d}=\frac{L_{b}}{a_{1} \cdot a_{2}}
$$

As this equation shows, if the shooting is by the parallel camera configuration and if the amount of right-left horizontal shift equals the distance between the observer's irises $\mathrm{Hc}=\mathrm{de}$, then linearity can be retained between the shooting distance to the object and the distance at which a stereoscopic image is formed. An example is shown in Fig, 6. This shows the relationship between the shooting distance $(\mathrm{Lb})$ and the distance to $3 \mathrm{D}$ images $(\mathrm{Ld})$ shot by the parallel camera configuration under the conditions shown in Table 2 . When an object is

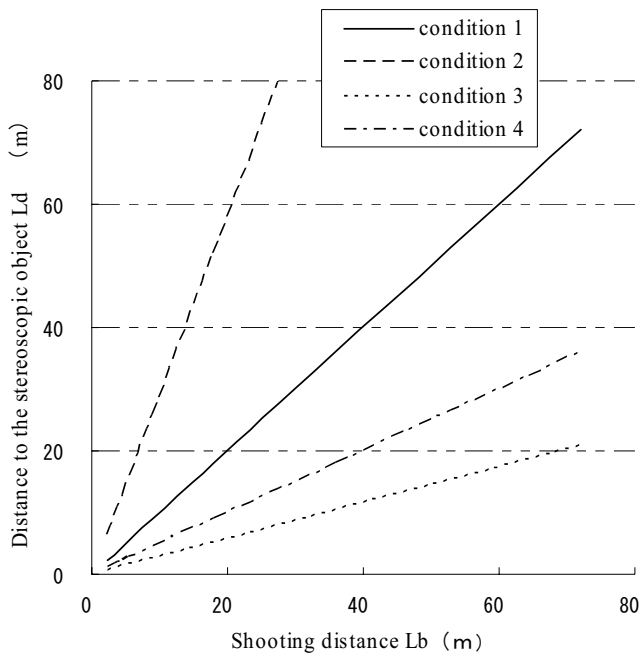

Fig. 6 Relation between shooting distance and the distance to the $3 \mathrm{D}$ objects shot by the parallel camera configuration 
shot by this camera configuration, the projected $3 \mathrm{D}$ image moves toward the viewer as the distance between the cameras widens, but it moves away from the viewer when the lens view angles expands.

\subsection{Toed-in camera configuration}

Unlike the parallel camera configuration, this shooting method moves the convergence point back and forth without creating a horizontal shift between right and left images.

Assuming that $\mathrm{Hc}=0$ in equation (7), we obtain:

$$
L_{d}=\frac{1}{\frac{1}{L_{s}}-\frac{a_{1} \cdot a_{2}}{L_{c}}+\frac{a_{1} \cdot a_{2}}{L_{b}}}
$$

Fig. 7 shows the relationship between the shooting distance $(\mathrm{Lb})$ and the distance to 3D images (Ld) shot by the toed-in camera configuration under the conditions shown in Table 2.

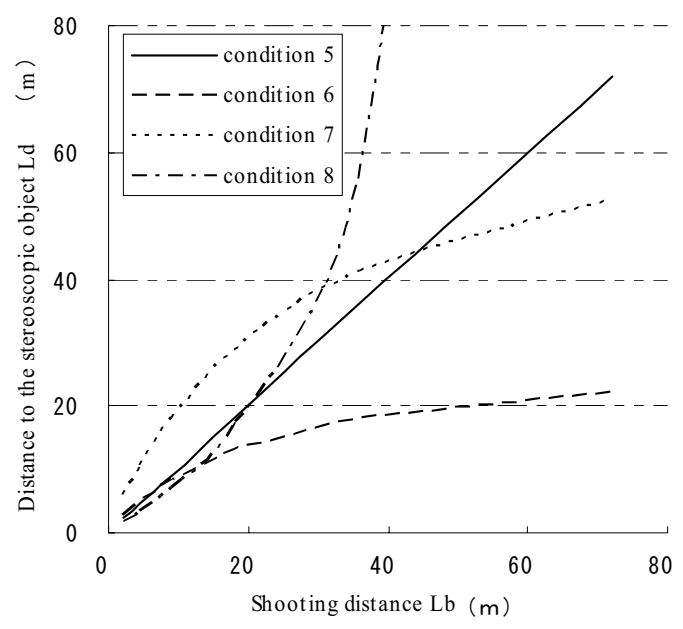

Fig. 7 Relation between shooting distance and the distance to the $3 \mathrm{D}$ objects shot by the toed-in camera configuration

By the toed-in camera configuration, as the graph shows, Ld begins to undergo a major change when $L_{c}=a_{1} \cdot a_{2} \cdot L_{s}$. When $L_{c}<a_{1} \cdot a_{2} \cdot L_{s}$, Ld cannot be calculated by equation (9) if the shooting distance $\mathrm{Lb}$ is large. This is a situation where the eyes do not converge (diverge) as the distance between the right-left images becomes greater than the space between the right-left irises. But, apparently, this situation does not immediately mean no-fusion. If $L_{c}=a_{1} \cdot a_{2} \cdot L_{s}$ (condition (5)), equation (9) becomes the same as equation (8), meaning that there is no distortion at the center of the screen, but that keystone distortion occurs in the peripheral area.
Table 2 Examples of shooting and viewing condition

\begin{tabular}{|c|c|c|c|c|c|c|c|c|}
\hline condition & 1 & 2 & 3 & 4 & 5 & 6 & 7 & 8 \\
\hline $\begin{array}{c}\text { camera } \\
\text { configuration }\end{array}$ & \multicolumn{4}{|c|}{ parallel } & \multicolumn{4}{|c|}{ toed-in } \\
\hline $\begin{array}{c}\text { camera } \\
\text { separation dc } \\
\text { (mm) }\end{array}$ & 65 & 30 & 90 & 130 & 65 & 65 & 32.5 & 130 \\
\hline $\begin{array}{l}\text { the angles of } \\
\text { view of lens } \alpha \\
\text { (degree) }\end{array}$ & 33.4 & 43.6 & 13.7 & 33.4 & 33.4 & 43.6 & 43.6 & 43.6 \\
\hline $\begin{array}{c}\text { convergence } \\
\text { distance Lc (m) }\end{array}$ & \multicolumn{4}{|c|}{$\infty$} & 4.5 & 4 & 1.8 & 6.1 \\
\hline $\begin{array}{l}\text { viewing angle } \beta \\
\text { (degree) }\end{array}$ & \multicolumn{8}{|c|}{33.4} \\
\hline $\begin{array}{c}\text { viewing } \\
\text { distance } L s(m)\end{array}$ & \multicolumn{8}{|c|}{4.5} \\
\hline $\begin{array}{l}\text { horizontal shift } \\
\mathrm{Hc} \text { (mm) }\end{array}$ & \multicolumn{4}{|c|}{65} & \multicolumn{4}{|c|}{0} \\
\hline al & 1.00 & 0.46 & 1.38 & 2.00 & 1.00 & 1.00 & 0.50 & 2.00 \\
\hline a2 & 1.00 & 0.75 & 2.50 & 1.00 & 1.00 & 0.75 & 0.75 & 0.75 \\
\hline $\mathrm{Lcial}^{*} 2^{*} \mathrm{Ls}$ & & & & & 1.00 & 1.19 & 1.07 & 0.90 \\
\hline
\end{tabular}

\section{CONCLUSIONS}

This paper reports on the setting of the optical axes of 3D cameras. The parallel camera configuration maintains linearity during the conversion from real space to stereoscopic images. But the toed-in camera configuration often can not maintain linearity during the conversion from real space to stereoscopic images.

\section{REFERENCES}

[1] A. J. Hill, "A Mathematical and Experimental Foundation for Stereoscopic Photography", Journal of SMPTE, Vol. 61, pp.461-486 (1953)

[2] E. Levonian, "Stereography and Transmission of Images", Journal of SMPTE, Vol. 64, pp.77-85 (1955)

[3] A. Woods, T. Docherty, R. Koch, "Image Distortions in Stereoscopic Video Systems", Proc. of SPIE Vol.1915, Stereoscopic Displays and Applications IV (1993)

[4] A. M. Ariyaeeinia, "Analysis and design of stereoscopic television systems", Signal processing: Image Communication 13, pp.210-208 (1998)

[5] R. Spottiswoode, N. L. Spottiswoode, C. Smith, "Basic Principles of the Three Dimensional Film”,SMPTE J. 59,pp.249-286 (Oct. 1952)

[6] H. Yamanoue, M. Nagayama, M. Bitou, J. Tanada, "Orthostereoscopic conditions for 3D HDTV" Proc. of SPIE Vol. 3295, Stereoscopic Displays and Virtual Reality Systems V (1998)

[7] H. Yamanoue, M. Okui, F. Okano and I. Yuyama, "Development of a Compact 3D HDTV Camera with Zoom Lens and Psychological Effects of the Images", IDW'99,3D2-3, pp.1071-1074, 1999 